\title{
Article \\ Algorithms for Detecting Cattle Diseases at Early Stages and for Making Diagnoses and Related Recommendations
}

\author{
Dmitry Yu. Pavkin ${ }^{1}\left(\mathbb{D}\right.$, Alexei S. Dorokhov ${ }^{1}$, Fedor E. Vladimirov ${ }^{1, *} \mathbb{C}$, Igor M. Dovlatov ${ }^{1}(\mathbb{D}$ \\ and Konstantin S. Lyalin ${ }^{2}$ \\ 1 Laboratory of Digital Systems and Robotic Technical Means in Animal Husbandry, Department of \\ Mechanization and Automation of Processes in Animal Husbandry, Federal State Budgetary Scientific \\ Institution «Federal Scientific Agroengineering Centre VIM», 109428 Moscow, Russia; \\ dimqaqa@mail.ru (D.Y.P.); vim@vim.ru (A.S.D.); dovlatovim@mail.ru (I.M.D.) \\ 2 Development Department, National Research University of Electronic Technology "MIET", \\ 124498 Moscow, Russia; ksl@miee.ru \\ * Correspondence: fvladimirov21@gmail.com; Tel.: +7-926-369-9243
}

Citation: Pavkin, D.Y.; Dorokhov, A.S.; Vladimirov, F.E.; Dovlatov, I.M.; Lyalin, K.S. Algorithms for Detecting Cattle Diseases at Early Stages and for Making Diagnoses and Related Recommendations. Appl. Sci. 2021, 11, 11148. https://doi.org/10.3390/ app112311148

Academic Editor: Giancarlo Mauri

Received: 12 October 2021

Accepted: 18 November 2021

Published: 24 November 2021

Publisher's Note: MDPI stays neutral with regard to jurisdictional claims in published maps and institutional affiliations.

Copyright: (c) 2021 by the authors. Licensee MDPI, Basel, Switzerland. This article is an open access article distributed under the terms and conditions of the Creative Commons Attribution (CC BY) license (https:// creativecommons.org/licenses/by/ $4.0 /)$.

\begin{abstract}
Analytical and theoretical studies were conducted in working cattle facilities in order to identify infectious, parasitic, and nervous diseases in large horned cattle. Our analytical study was based on the analysis of available scientific research papers. The theoretical research was based on processing the measurement results with existing hardware and software. Both environmental and physiological parameters were obtained from five farms for at least 30 days. The studied cows were divided into two groups. One group consisted of 37 dairy cows of the Holstein breed aged 2-3 years having no clinical signs of disease. All cows in this group were fed the same diet, kept in the same conditions, and had the same lactation period (from 3 to 5 months). Their average weight was $517( \pm 2.03) \mathrm{kg}$. For inclusion into the second group, we selected 23 dairy cows with parameters similar to those of the cows in the first group but with some clinical signs of diseases such as encephalomyelitis, infectious enteritis, and hypodermatosis. The data obtained from the animals in the first group were considered as the parameters' standardized boundary values for the estimation of a cow's conditions, i.e., as the norm (the setpoint). As for the data obtained for the second group, they were considered to be deviations from the threshold values of the parameters (deviations from the setpoint, which required a pre-planned action). The analysis was carried out using the program code implemented in the software package "Matlab R2019b". We analyzed the correlations between the cows' rumen temperature and $\mathrm{pH}$, their locomotive activity, and environmental parameters such as air temperature and relative humidity in the cowsheds. We then constructed graphs of inter-correlating functions. As a result of the study, for the first time, algorithms were compiled enabling the detection of infectious, parasitic, and nervous diseases.
\end{abstract}

Keywords: horned cattle; diseases; development; algorithm; non-invasive measurement method

\section{Introduction}

The introduction of technological innovations for intensive cattle growing and the breeding of high-yielding cows is tightly connected with an increase in diseases incidence. Livestock diseases cause significant economic damage due to the high frequency of their propagation in the Russian Federation and abroad. For example, annually in Europe, up to $50 \%$ of cows are culled due to diseases of their extremities resulting in their low productivity and reduced reproductive capacity [1,2].

Potentially, a continuous non-invasive monitoring of cattle conditions based in various techniques can become a powerful tool for monitoring cattle's physiological state on feedlots and in dairy production. Such monitoring can also allow the early detection of diseases; therefore, diagnoses will be made faster than with the aid of traditional methods of clinical assessment. Besides, the accuracy and the specificity of the traditional 
clinical assessment of cattle diseases leave much to be desired. On the other hand, the remote early detection of diseases with the aid of advanced technological systems can improve remarkably the accuracy and timeliness of disease detection. In addition, the continuous monitoring of cattle behavior based on advanced technology can provide important information useful for treatment determination or the recognition of a cow state as a temporal event in research of animals' health and well-being [3-5].

Changes in animals' behavior represent one of the most important criteria for the assessment of animals' well-being and health [6-8]. The parameters of animals' behavior can be used for the development of a system for the early prevention of diseases. For example, hoof injuries cause lameness, which make cows prefer laying instead of walking, thus decreasing their locomotive activity [9-11].

A restless behavior of a sick animal can begin prior to the appearance of any of the main clinical symptoms of a disease. For example, cows react less vividly to external stimuli and their activity decreases a few hours before their temperature rises due to mastitis [12,13]. Besides, the circadian rhythm of cattle's locomotive activity can decrease as early as two days before the clinical symptoms of this disease are detected [14]. Hence, it is possible to use these behavioral deviations as early signs of diseases, detect and treat them at a very early stage, and thus reduce the cost of medicines for cattle.

Until recently, it was difficult to detect such changes in behavior on a regular basis; therefore, the employees of livestock farms had to monitor the animals continuously. Today, hi-tech sensors and tools are available for the implementation of the so-called "precision animal husbandry". They enable continuous monitoring of the animals' physiological state. Accelerometers can register acts of movement, positioning systems can detect animals' positions, $\mathrm{pH}$ meters can measure the acidity of the animals' rumen. and temperature sensors can provide caregivers with additional important health data [15].

The rumen temperature measured orally (by a sensor in the animal's mouth) has a strong correlation with the rectal temperature; thus, the rumen temperature can be considered as the body temperature [16]. According to previous studies, the use of oral sensors for temperature measurement is a less invasive and yet reliable method to detect an increase of temperature in the cow's body [17,18].

However, the question is not how to collect the data, but rather how to process them. In particular, in order to detect early signs of diseases based on cattle behavior, it is necessary to know the animals' normal state and to predict and assess deviations from this norm. The development of algorithms for the interpretation of cattle behavior may help significantly [19-21].

Berckmans (2013) highlighted that in the algorithm development process, different types of variables can be used and need to be defined in advance [22].

The level of feeding is described as one of the most important indicators of animals' health and well-being. It can be influenced by environmental factors such as food components, ambient temperature, conditions of keeping, and even group size. The level of water consumption is closely related to the feeding process [23-25]; therefore, similar factors can also affect this indicator.

In their study, Das et al. (2016) revealed that any prolonged period of high temperature combined with high relative humidity of the air negatively affect food intake (decreased to $40 \%$ ), milk production (decreased to 50\%), and reproductive efficiency (decreased to 60\%); at the same time, dramatically, the combination of these factors increases the probability of contracting parasitic diseases (by $43.3 \%$ ) [26].

Sejian et al. (2013) found that during heat stresses, the number of the white blood cells in cattle increased by $21-26 \%$, and the number of the red blood cells decreased by $12-20 \%$. This negatively affected the animals' health and caused various diseases [27].

This study aimed to develop algorithms for the detection of possible/incipient diseases in cattle; these algorithms are intended for digital systems for the internal monitoring of cattle physiological state. 


\section{Materials and Methods}

The study was conducted by analyzing the available statistical data obtained in the course of practical studies conducted in real conditions in 5 large farms: "Ecocorm" Ltd. (Voronezh region, Russia), "Research Center of Traditional Technologies" Ltd. (Ivanovo region, Russia), Agricultural enterprise "Novomarkovskoye" Ltd. (Voronezh region, Russia), Agricultural enterprise "Voshchazhnikovo" Ltd. (Yaroslavl region, Russia). Thirty-seven heads of cattle were examined for 30 days with a measurement interval of $60 \mathrm{~s}$. The cows' selection for the examination was carried out in accordance with the following criteria: all cows were of the same breed (specifically, the Holstein breed), they were kept in the same conditions, and received the same unified diet. They were aged 2 or 3 years; all of them had their lactation period of 3 to 5 months, and their weight was at least $350 \mathrm{~kg}$. Their average milk yield at the peak lactation was $30( \pm 3) \mathrm{kg} /$ day. Their daily diet consisted of alfalfa hay $(2.5 \mathrm{~kg})$, corn silage $(16.0 \mathrm{~kg})$, alfalfa haylage $(12.0 \mathrm{~kg})$, propylene glycol $(0.2 \mathrm{~kg})$, glycerin $(0.15 \mathrm{~kg})$, and compound feeds $(8.78 \mathrm{~kg})$.

Prior to the start of the study, the selected cows were examined in accordance with the common clinical examination procedure [5]. The clinical study used an algorithm involving the following sequential steps: anamnesis of the studied animals, their identification, habitus determination, examination of wool and skin, examination of visible mucous membranes, measurement of body temperature, palpation, auscultation, percussion and live weight measurement.

The average body weight of the studied cows was $517( \pm 2.03) \mathrm{kg}$. No clinical signs of disease were found in the first group.

For inclusion into the second group, 23 cows were selected with parameters similar to those of the cows in the first group but with the presence of some clinical signs of diseases such as encephalomyelitis, infectious enteritis, and hypothermia. In animals belonging in the second group, 3 groups of diseases were observed, namely, nervous, infectious, and parasitic diseases. The diseases of the nervous system include encephalitis, encephalomyelitis, and meningitis. Among the infectious diseases, the following ones were considered: brucellosis, infectious nodular dermatitis, and tuberculosis. As parasitic diseases, we evaluated hypodermatosis, cysticercosis and dictyocaulosis.

The input data were the measurements readings of the indicators of cattle health $(\mathrm{pH}$ level, rumen temperature, and locomotive activity). This preliminary data were obtained using the internal monitoring system prior to the main data collection. The measurements were carried out using sensors entered orally. Besides, microclimate parameters were measured, such as relative humidity and air temperature in the cowshed. Data monitoring was conducted via a radio transmitter on the ISM band ( $433 \mathrm{MHz})$. The combined database of cattle locomotive activity, $\mathrm{pH}$ level, and rumen temperature was transmitted via the basic station and then via a GSM module or Ethernet cable to the server.

The microclimate in the premises, where healthy cows of the first group were kept, was within the normal range (humidity $70-85 \%$, temperature $10-20{ }^{\circ} \mathrm{C}$ ). Deviations were observed within acceptable limits of the values (humidity $5-7 \%$, temperature $3-10{ }^{\circ} \mathrm{C}$ ). Meanwhile, in the parameters of the microclimate in the rooms where the sick cows were kept, deviations from the norms were periodically observed (humidity below $50 \%$, tem-perature above $25^{\circ} \mathrm{C}$ ).

The measurement accuracy of the sensors was checked with the use of samples of the rumen content taken from fistulated cows. These samples were examined in our laboratory by veterinarians with the use of the standard stationary measuring devices. It was found that the deviations in the measured parameters were statistically insignificant (not exceeding 0.05).

The values of the rumen temperature, motor activity, and rumen $\mathrm{pH}$ for the cows in the first group were taken as the standardized boundary values of the ranged parameters; that is, when a cow presented values of the measured parameters similar to those of the group 1, the health condition of this cow was estimated as normal (as the setpoint). In contrast to the norm, The measured parameters' values of the cows in the second group 
were considered as deviations from the setpoints, i.e., as deviations from the threshold values, which requested a predetermined action.

Based on the values obtained from sick cows, the main criteria were identified for 3 types of diseases (nervous, inflammatory, and parasitic).

In order to develop the algorithms, at first, we developed a program code in the software environment "Matlab R2019b" (Matrix Laboratory, the company "The MathWorks", Natick, MA, USA). The available data were entered into this software environment, and then correlations between the measured indicators were calculated and graphs were obtained. Based on these results and taking into account the information from the analyzed scientific literature, we developed algorithms for the detection of infectious, parasitic, and nervous diseases.

\section{Results}

The analysis of the data obtained from the cows of the first group revealed the following facts:

- when cattle graze on a pasture, their motor activity is characterized by a very large amplitude of acts of movement (at least 20 units in $10 \mathrm{~min}$ );

- $\quad$ the duration of the increased activity is quite long (at least $2 \mathrm{~h}$ per day);

- this pattern is repeated regularly within a long period of time, more than two weeks (Figure 1a);

- $\quad$ when walking on a pasture, cows can increase the temperature of their bodies (Figure 1b).

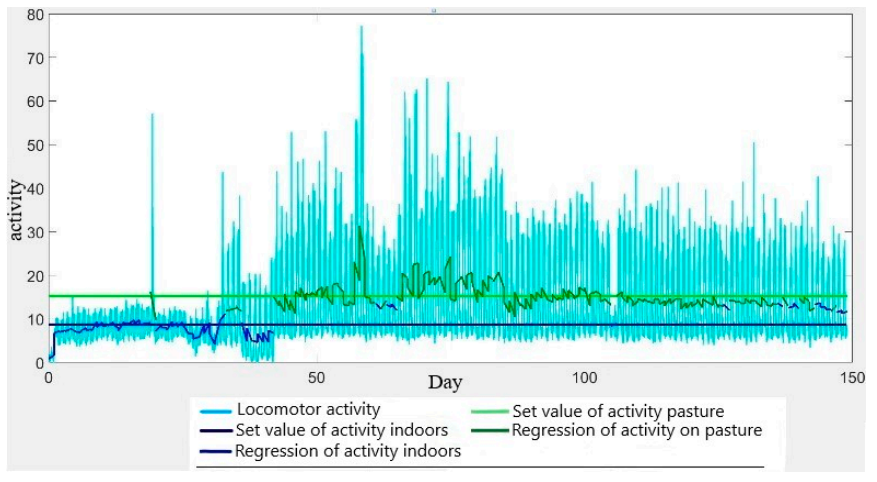

(a)

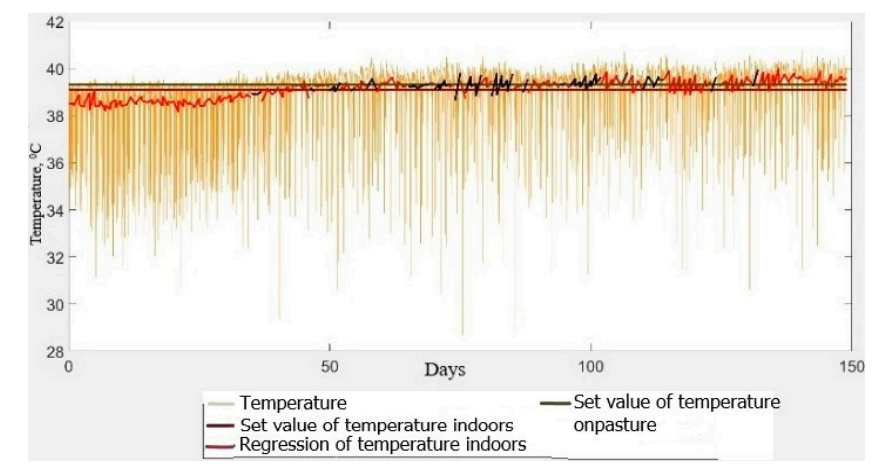

(b)

Figure 1. Example of physiological data displaying in the software environment "Matlab". (a) Difference in locomotive activity levels on pasture and indoors; (b) difference in rumen temperature on pasture and indoors.

The modern devices offered on the market are oriented in such a way that the y-axis represents a cow's vertical movements (of head and legs), the x-axis is parallel to the cow body (i.e., to the direction of its walking), and the z-axis is located sideways to the cow (i.e., the z-axis reflects a cow's movements to the left and to the right) (Figure 2a).

When considering a healthy cows' movements, in this case from the point of view of physical processes, it is proposed to consider the leg movements as a sinusoid of a pendulum oscillation. Thus, the physical processes of the oscillation are evaluated with the purpose to perform a diagnosis based on the cow's motor activity (Figure 2b).

As for walking, cows in the second group showed typical deviations corresponding to fluctuations in the graph of cows' activity (the sinusoid was either ahead of the initial state or behind it); in contrast, cows in the first group presented a normal motor activity. A precise evaluation of this sign will allow the diagnosis of any deviation from the normal motor activity.

Figure 3 shows the graphs of the normal activity of the animals of the first group: the graphs are uniform and stable, and the activity index, on average, is not lower than 10. 


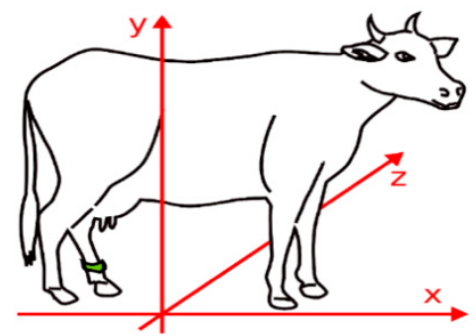

(a)

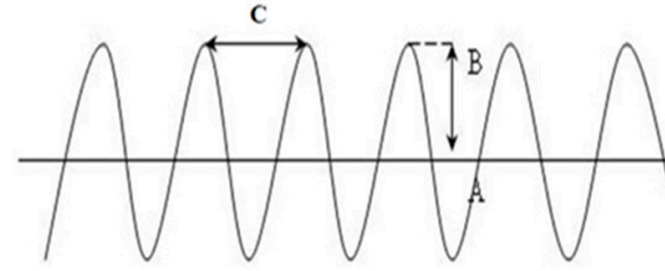

(b)

Figure 2. Analysis of cattle's motor activity. (a) Measuring principle for cows' motor activity; (b) cow's activity in terms of its legs' oscillatory (pendulum) movements; (A) amplitude of oscillations at the cow's upper point (head); (B) amplitude of oscillations at the cow's lower point (leg); (C) oscillation period.

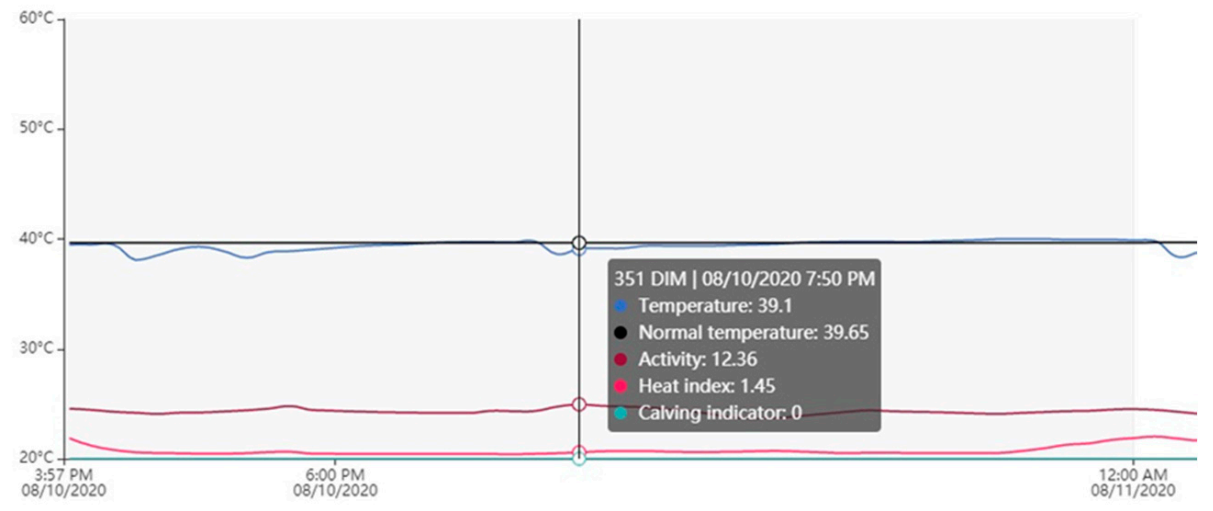

Figure 3. Activity graph for a cow of the first group (normal).

In contrast, Figure 4 shows the activity graph of one animal of the second group suffering from infectious enteritis (the activity index is below 5).

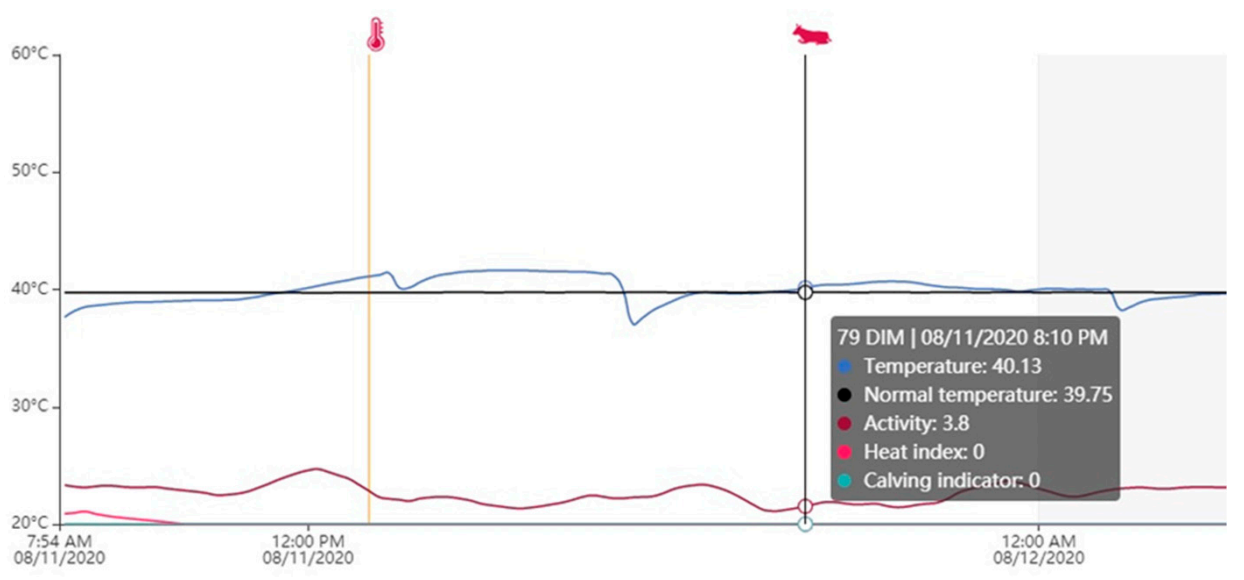

Figure 4. Activity graph for an animal of the second group suffering from infectious enteritis.

The graph in Figure 4 regards one cow and is shown as an example; for other cows in the second group, the activity graphs are similar.

Thus, diseases contribute to decreasing animals' motor activity level.

In addition to tracking the primary reaction of an animal when exposed to a particular factor, we also recorded the number of animals' rest periods within a day, the average duration of one rest period, and the total duration of the resting time. The results are presented in Table 1. 
Table 1. Main parameters of animals' motor activity in normal conditions, during the heat and under stress or disease.

\begin{tabular}{cccc}
\hline Groups & $\begin{array}{c}\text { Number of Rest } \\
\text { Periods/Day }\end{array}$ & $\begin{array}{c}\text { Average Duration of a Rest } \\
\text { Period, Minutes }\end{array}$ & $\begin{array}{c}\text { Duration of Rest, } \\
\text { Minutes/Day }\end{array}$ \\
\hline 1st group $(n=37)$ & $12.30 \pm 0.24^{*}$ & $66.33 \pm 1.05^{* *}$ & $753.91 \pm 8.45^{* *}$ \\
\hline 2nd group $(n=23)$ & $11.33 \pm 0.92$ & $69.67 \pm 4.40$ & $801.02 \pm 38.42$ \\
\hline
\end{tabular}

${ }^{*},{ }^{* *}$ Parameters of the motor activity of cows during estrus, stress and disease.

As can be seen from the data represented in the Table 1, the shortest duration of the motor activity was observed for sick animals of the second group (801 min/day), which was on average $47 \mathrm{~min}$ longer than that for healthy animals. The differences between the groups are significant $(p<0.05)$.

In animals belonging to the second group, three groups of diseases were observed, namely, nervous, infectious, and parasitic diseases. The diseases of the nervous system included encephalitis, encephalomyelitis, and meningitis. Among the infectious diseases, we found brucellosis, infectious nodular dermatitis, and tuberculosis. The parasitic diseases comprised hypodermatosis, cysticercosis, and distioculosis.

The input data for the algorithms were the values of the analyzed parameters of rumen temperature, rumen $\mathrm{pH}$, locomotive activity, relative humidity and air temperature in the cowsheds (Figure 1).

After data array processing by the program code, the program plotted the crosscorrelation functions and also output a numeric array (Figure 5).

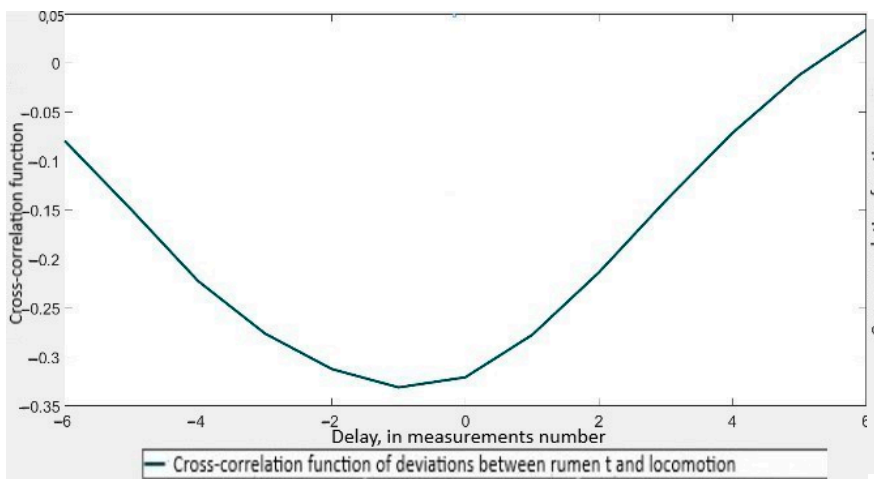

(a)

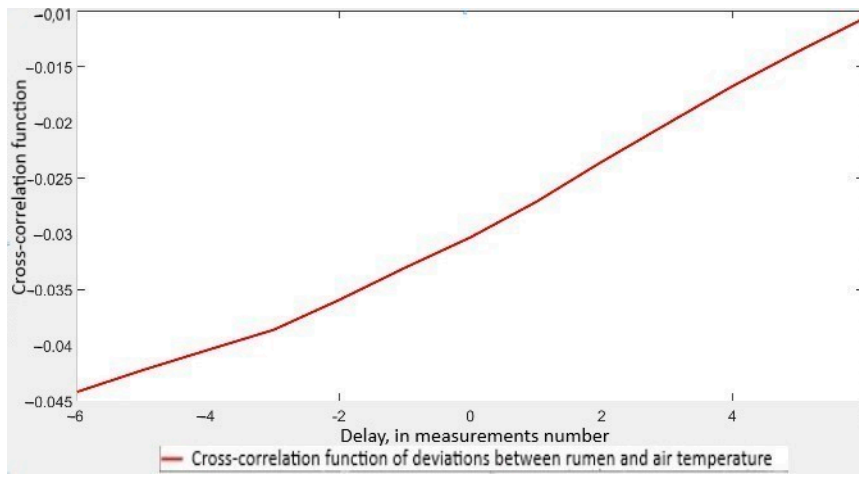

(c)

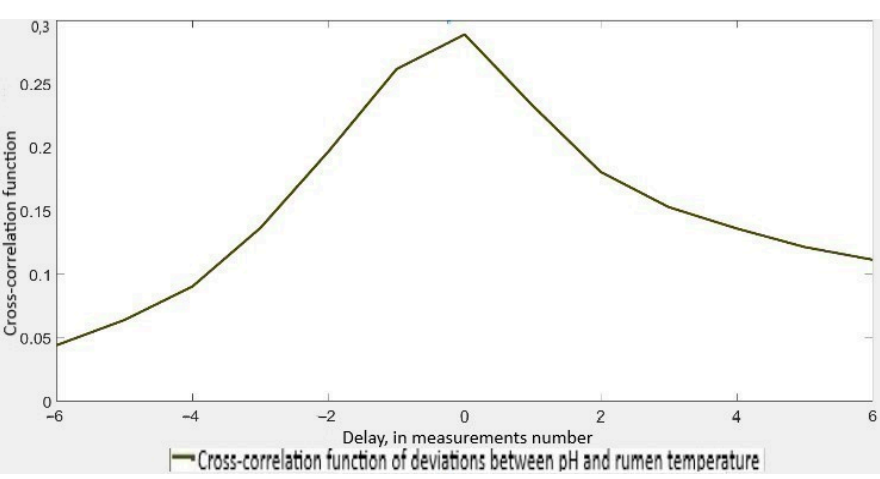

(b)

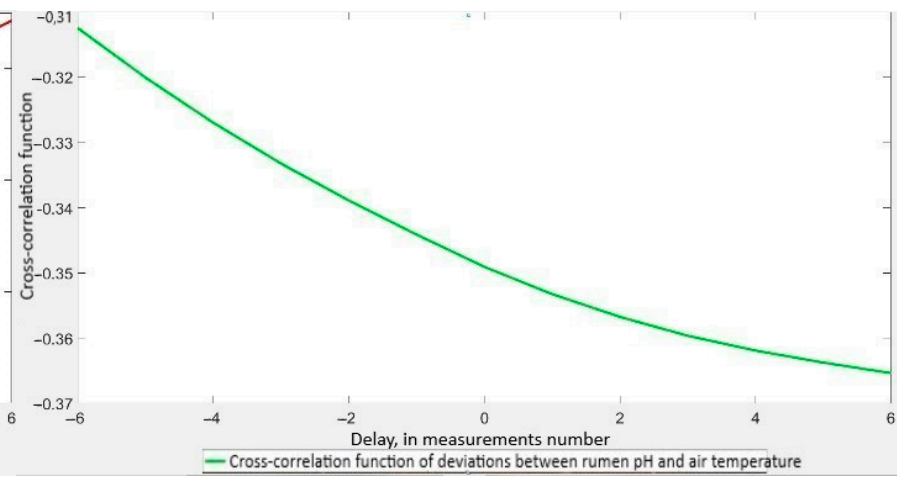

(d)

Figure 5. Functions of cross-correlations between physiological indicators of cattle health and microclimate parameters. (a) Cross-correlation function of rumen temperature and physical activity level; (b) cross-correlation function of rumen temperature and rumen $\mathrm{pH}$ value; (c) cross-correlation function of rumen temperature and ambient air temperature; (d) cross-correlation function of rumen $\mathrm{pH}$ value and ambient air temperature. 
In order to identify functions, dependencies, and correlations, statistical processing of the data array was carried out by the method of random variables. It was performed using the Formulas (1) and (2)

$$
r_{X Y}=\frac{\sum_{i=1}^{N}\left(X_{i}-\bar{X}\right)\left(Y_{i}-\bar{Y}\right)}{\sqrt{\sum_{i=1}^{N}\left(X_{i}-\bar{X}\right)^{2}\left(Y_{i}-\bar{Y}\right)^{2}}},
$$

where $N$ is the measurements number, $X_{i}$ and $Y_{i}$ are results of the $i$ th measurement, $\bar{X}$ and $\bar{Y}$ are average values.

The normalized cross-correlation function of the random variables $X$ and $Y$ is an analogue of the linear correlation coefficient, with the only difference that one of the arrays is shifted several positions to the right or to the left:

$$
f(j)=\frac{\sum_{i=1}^{N-j}\left(X_{i}-\bar{X}\right)\left(Y_{i+j}-\bar{Y}\right)}{\sqrt{\sum_{i=1}^{N-j}\left(X_{i}-\bar{X}\right)^{2}\left(Y_{i+j}-\bar{Y}\right)^{2}}},
$$

where $f(j)$ is the cross-correlation function, and $j$ is delay (in measurements number).

From the analysis of the cross-correlation function on the Cheddock scale, we found that when measuring both the rumen temperature and the locomotive activity level at any given instant of time, a moderate negative correlation was observed, i.e., with a statistically significant probability, a decrease in one of the values meant an increase in the other one (Figure 6a).

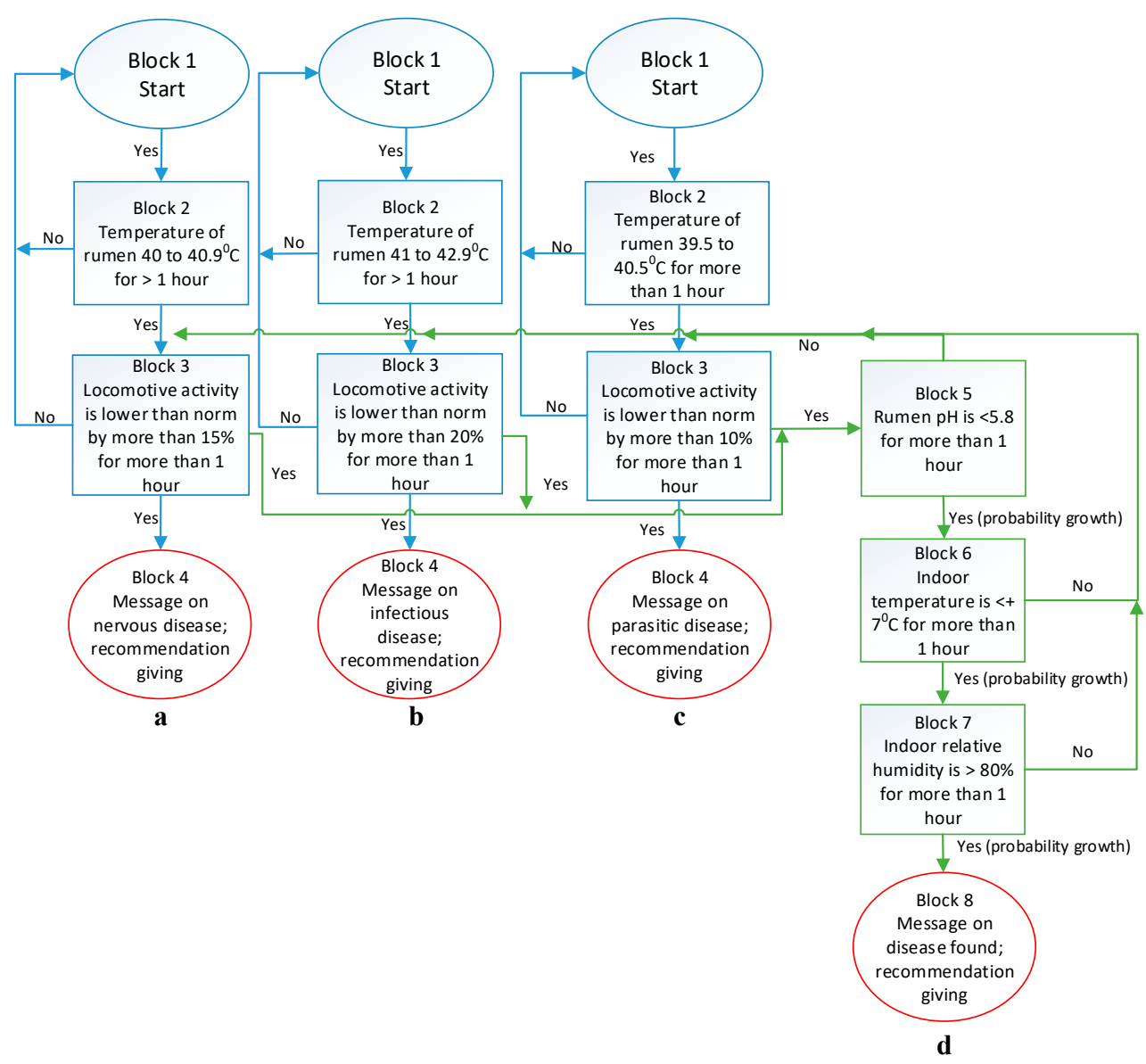

Figure 6. Algorithms for diseases detection. (a) Algorithm for the detection of nervous system diseases; (b) algorithm for the detection of infectious diseases; (c) algorithm for the detection of parasitic diseases; the blue blocks indicate algorithms' main criteria; (d) the green blocks indicate for additional criteria; the red blocks indicate the end of the algorithms. 
For measurements of rumen temperature and rumen $\mathrm{pH}$, a moderate positive correlation between the values was observed, i.e., an increase in rumen temperature was more often associated with an increase in the $\mathrm{pH}$ than with a decrease; however, the difference in the frequency was rather insignificant (Figure 6b).

For measurements of rumen temperature and air temperature in cowsheds, a remarkable negative correlation was observed, i.e., in an hour, any change in air temperature in the cowsheds had an impact on the rumen temperature (Figure 6c).

For measurements of rumen $\mathrm{pH}$ and air temperature in the cowsheds, regardless of how they were made, i.e., simultaneously or in conditions of various delays, a moderate negative correlation was observed, i.e., the air temperature affected the rumen $\mathrm{pH}$ value within an hour after the measurements were taken (Figure $6 \mathrm{~d}$ ).

The average $\mathrm{pH}$ of the rumen in the group under consideration was 6.08; the standard deviation $( \pm)$ was 0.29 . The average rumen temperature in the group under consideration was $38.92( \pm 0.19)$. The average level of the locomotive activity in the group under consideration was $8.6( \pm 1.4)$.

The highest modulus average value of the linear correlation coefficients was -0.222 $( \pm 0.117)$; it was reached between the locomotive activity levels and the rumen $\mathrm{pH}$ values.

For some animals, the linear correlation coefficient reached -0.519 ; this correlation was observed between $\mathrm{pH}$ level and locomotive activity; hence, this was a noticeable correlation and suggested a stable connection. The correlation between the parameters of rumen temperature and locomotive activity level in some cows reached -0.424 , and the same was observed for the correlation between rumen temperature and $\mathrm{pH}$ level that reached -0.470 , which is also close to what can be called a moderate correlation and can suggest a stable mutual connection.

As a result of the analysis of the mutual correlation functions, the following values were obtained: between rumen temperature and locomotive activity, a correlation value of 0.33 ; between temperature and rumen $\mathrm{pH}, 0.29$; between rumen $\mathrm{pH}$ and air temperature, 0.37 ; between rumen $\mathrm{pH}$ and locomotive activity, 0.16 ; between rumen $\mathrm{pH}$ and relative humidity, 0.29; between locomotive activity level and relative humidity, 0.37; between locomotive activity level and air temperature, 0.62 ; between rumen temperature and relative humidity, 0.18 .

It should also be noted that we found a statistically insignificant correlation between the parameters of rumen temperature and ambient air temperature $(-0.05)$ in the absence of abnormal ambient temperature conditions.

Based on the obtained criteria and graphs of the cross-correlation functions, algorithms were developed for the detection of infectious, nervous, and parasitic diseases (Figure 6a-d). As shown in Figure 6, we took into account both the main health criteria, namely, rumen temperature and physical activity level, and additional ones such as rumen $\mathrm{pH}$ and indoor air parameters (temperature and humidity).

When issuing a message about the presence of a disease in a particular group of cows, the algorithm provides general recommendations on how to minimize the further development of the clinical signs.

To improve the detection, some additional conditions were checked, whose fulfillment increased the probability of each disease being more severe (Figure $6 \mathrm{~d}$ ).

It should be noted that, first of all, the mathematical model (written based on the obtained algorithms) calculated the animals' location (cattle house or pasture). This was done because the animals' motor activity differs depending on the conditions in which they are kept (loose or stable-walking conditions (when there is some motion)); however, this difference is unrelated to any disease. In connection with this, for the two locations, the setpoint (and, as a result, the standard deviation and regression) was different. The animal location determination was done based on the analysis of motor activity amplitude. However, due to the difference in the individual characteristics of the animals, the amplitudes of their motor activity differed significantly. That is why the data on the animals' location should be considered as approximate. In this regard, in order to obtain more accurate 
information, it is recommended to consider the possibility of registering the grazing time in a journal and subsequently transfer this information to the owner. In this case, it would be possible to improve and finalize the computer program.

\section{Discussion}

The existing algorithms for detecting deviations in indicators of the physiological state of cattle do not consider the location of the animals under study (cows are in the pasture or in the barn). That is why we conducted a comparative analysis of the motor activity index of both sick and healthy dairy cows. The cows of the second group presented deviations in frequency and amplitude of their legs' oscillatory (pendulum) movements when walking (the sinusoid was ahead of the normal sinusoid or lagged behind it). Meanwhile, all parameters were within the normal range for the cows of the first group.

The animals' activity index for the first group was on average not less than 10 units, while for the second group, it was below 5 units. The lowest duration of the motor activity was observed in sick animals of the second group: their rest time was $801 \mathrm{~min} /$ day, which was longer on average by $47 \mathrm{~min}$ (by $6 \%$ ) than that of heathy cows. The differences between the groups are statistically significant $(p<0.05)$.

Davison et al. (2020) came to the conclusion that the consideration of the locations was necessary to identify deviations from the physiological state in in milk cows. It is important because, for example, heat stress significantly affects the body temperature and the locomotive activity of animals; therefore, not always deviations from the norm would be associated with diseases [28]. Ramón-Moragues et al. (2021) revealed that under heat stress, cows noticeably decreased their locomotive activity and body temperature; besides, there was a violation of the animals' daily routine [29]. Rutherford et al. (2019) came to the conclusion that the rumen temperature varies greatly depending on the animals' location. For example, when being in a pasture, due to the predominance of succulent feed in the diet, the rumen $\mathrm{pH}$ was below normal, while its temperature was higher than the norm [30]. The indoor microclimate has a connection with animals' measured values. For example, a temperature above $+20^{\circ} \mathrm{C}$ causes heat stress: energy consumption increases for the maintenance of body optimal temperature, as a result of which the costs of other processes decrease, and immune activity decreases [31]. In high humidity, it is more difficult for an animal's body to cope with infectious diseases; animals' metabolism slows down, their blood flow becomes disordered, and the level of hemoglobin in their blood decreases [32]. For this reason, when creating algorithms, it is necessary to take into account the animals' location.

As for the identification of correlations between the physiological state's parameters of cattle, we confirmed successfully the results obtained in the previous studies.

Additionally, we obtained the following data: the average value of the linear correlation coefficients for rumen temperature and locomotive activity was $0.199(=0.088)$, and that between level of locomotive activity and rumen $\mathrm{pH}$ was $-0.222(=0.117)$. Between $\mathrm{pH}$ level and level of locomotive activity of the animals, the linear correlation coefficient reached -0.519 , which suggests the presence of a stable connection between these parameters. The correlation between rumen temperature and locomotive activity level reached -0.424 , and that between rumen temperature and rumen $\mathrm{pH}$ level was -0.470 , which also suggests a stable connection. The analysis of the cross-correlation function showed a noticeable connection between level of locomotive activity and air temperature (0.622); moderate correlations were observed between rumen temperature and locomotive activity (0.33), between rumen $\mathrm{pH}$ and air temperature $(-0.36)$, and between level of locomotive activity and relative humidity $(-0.347)$.

Similar results regarding the high correlation between the studied cattle's physiological parameters were obtained by Alzahal et al. (2008) and by Antanaitis et al. (2016). The research results by Dorokhov et al. (2021) showed a negative statistically significant correlation $(\mathrm{r}=-0.932, p<0.01)$ between rumen temperature and its $\mathrm{pH}[33-35]$. 
Soriani et al. revealed a significant correlation between rectal temperature and the temperature-humidity index (THI) $(r=-0.41 ; p<0.01)$. In this regard, it is very important to take the microclimate into account, when developing algorithms for disease detection [36].

Based on the analysis of the scientific literature, three main groups of cattle diseases were identified: infectious, invasive (parasitic), and nervous (nervous system diseases) (Bessarabov et al. 2007; Isimbekov et al. 2016). These authors described the main criteria to diagnose these diseases (Figure 6) and how they can be detected at the initial stages of their development before the appearance of the main clinical signs; they also provided recommendations for their treatment [37,38].

As for the existing monitoring systems, they do not allow detecting diseases in their early stages because the algorithms used are outdated. Wang et al. (2018) highlighted, for example, that it is difficult to assess the level of feeding by using only an accelerometer; however, the combination of these data with those from other sensors would improve the assessment by as much as $20 \%$. This principle can be applied to the rest of the measured physiological parameters of cattle [39].

\section{Conclusions}

We developed algorithms to detect signs of nervous, parasitic, and infectious diseases in cattle and to issue recommendations based on changes in cows' physiological parameters. The developed algorithms are based on the results of both analytical research and field tests. The algorithms were obtained through the comparison of cows with similar reproductive status and physiological parameters, kept in the same conditions, and divided into two groups: sick and healthy animals.

Currently, the developed algorithms are used in the software called "Systems of internal monitoring of cattle's physiological state" («Federal Scientific Agroengineering Centre VIM», Moscow, Russian Federation).

Supplementary Materials: The following are available online at https:/ /www.mdpi.com/article/ 10.3390/app112311148/s1, Data S1: Initial data and results.

Author Contributions: Conceptualization, A.S.D. and F.E.V.; methodology, D.Y.P. and I.M.D.; software, F.E.V. and K.S.L.; validation, F.E.V. and I.M.D.; formal analysis, A.S.D. and D.Y.P., investigation, F.E.V. and K.S.L.; resources, A.S.D.; data curation, D.Y.P.; writing-F.E.V. and I.M.D.; writing-review and editing, A.S.D. and D.Y.P.; visualization, F.E.V. and K.S.L.; supervision, A.S.D.; project administration, A.S.D. and D.Y.P.; funding acquisition, F.E.V. All authors have read and agreed to the published version of the manuscript.

Funding: This work was supported by the Ministry of Education and Science of the Russian Federation in the framework of the State Assignment of "Federal Scientific Agroengineering Center VIM" (task No. 0581-2021-0009).

Institutional Review Board Statement: The study was conducted according to the guidelines of the Declaration of Helsinki and approved by the Institutional Review Board of Federal State Budgetary Scientific Institution «Federal Scientific Agroengineering Centre VIM» (Protocol code No. 270 dated 13 May 2019).

Informed Consent Statement: Written informed consent has been obtained from the patients to publish this paper.

Data Availability Statement: The data presented in this study are available in supplementary material.

Conflicts of Interest: The authors declare no conflict of interest.

\section{References}

1. Polyantsev, N.I. Technology of Reproduction of Breeding Cattle: Manual; Lan': Saint Petersburg, Russia, 2014; p. 288.

2. Buisman, L.L.; Alsaaod, M.; Bucher, E.; Kofler, J.; Steiner, A. Objective assessment of lameness in cattle after foot surgery. PLoS ONE 2018, 13, e0209783. [CrossRef] [PubMed] 
3. Ducrot, C.; Bed'Hom, B.; Béringue, V. Issues and special features of animal health research. Vet. Res. 2011, 42, 1. [CrossRef] [PubMed]

4. Jensen, M.B. Behaviour around the time of calving in dairy cows. Appl. Anim. Behav. Sci. 2012, 139, 195-202. [CrossRef]

5. Kocharyan, V.D.; Chizhova, G.S.; Shabasheva, Y.G. Methods of Agricultural Animals' Diagnosing and Treatment: Manual; Volgograd Federal State University of Civil Engineering: Volgograd, Russia, 2015; p. 100.

6. Lima, S.F.; Teixeira, A.G.V.; Higgins, C.H. The upper respiratory tract microbiome and its potential role in bovine respiratory disease and otitis media. Sci. Rep. 2016, 6, 29050. [CrossRef] [PubMed]

7. Bisdorff, B.; Schauer, B.; Taylor, N.; Rodríguez-Prieto, V.; Comin, A.; Brouwer, A.; Dórea, F.; Drewe, J.; Hoinville, L.; Lindberg, A.; et al. Active animal health surveillance in European Union Member States: Gaps and opportunities. Epidemiol. Infect. 2017, 145, 802-817. [CrossRef]

8. Gaeta, N.C.; Lima, S.F.; Teixeira, A.G.; Ganda, E.K.; Oikonomou, G.; Gregory, L.; Bicalho, R.C. Deciphering upper respiratory tract microbiota complexity in healthy calves and calves that develop respiratory disease using shotgun metagenomics. J. Dairy Sci. 2017, 100, 1445-1458. [CrossRef]

9. Alsaaod, M.; Büscher, W. Detection of hoof lesions using digital infrared thermography in dairy cows. J. Dairy Sci. 2012, 95, 735-742. [CrossRef] [PubMed]

10. Alsaaod, M.; Syring, C.; Dietrich, J.; Doherr, M.; Gujan, T.; Steiner, A. A field trial of infrared thermography as a non-invasive diagnostic tool for early detection of digital dermatitis in dairy cows. Veter. J. 2014, 199, 281-285. [CrossRef]

11. Bobić, T.; Mijić, P.; Gregić, M.; Bagarić, A.; Gantner, V. Early detection of the hoof diseases in Holstein cows using thermovision camera. Agric. Conspec. Sci. 2017, 82, 197-200.

12. Schirmann, K.; Chapinal, N.; Weary, D.; Vickers, L.; Von Keyserlingk, M. Short communication: Rumination and feeding behavior before and after calving in dairy cows. J. Dairy Sci. 2013, 96, 7088-7092. [CrossRef]

13. Dahl, M.O.; De Vries, A.; Maunsell, F.P.; Galvao, K.N.; Risco, C.A.; Hernandez, J.A. Epidemiologic and economic analyses of pregnancy loss attributable to mastitis in primiparous Holstein cows. J. Dairy Sci. 2018, 101, 10142-10150. [CrossRef] [PubMed]

14. Van Soest, P.J.; Robertson, J.B.; Lewis, B.A. Methods for Dietary Fiber, Neutral Detergent Fiber, and Nonstarch Polysaccharides in Relation to Animal Nutrition. J. Dairy Sci. 1991, 74, 3583-3597. [CrossRef]

15. Dolecheck, K.A.; Silvia, W.J.; Heersche, G., Jr.; Chang, Y.M.; Ray, D.L.; Stone, A.E.; Wadsworth, B.A.; Bewley, J.M. Behavioral and physiological changes around estrus events identified using multiple automated monitoring technologies. J. Dairy Sci. 2015, 98, 8723-8731. [CrossRef] [PubMed]

16. Knauer, W.; Godden, S.; McDonald, N. Technical note: Preliminary evaluation of an automated indwelling rumen temperature bolus measurement system to detect pyrexia in preweaned dairy calves. J. Dairy Sci. 2016, 99, 9925-9930. [CrossRef] [PubMed]

17. Adams, A.; Olea-Popelka, F.; Roman-Muniz, I. Using temperature-sensing reticular boluses to aid in the detection of production diseases in dairy cows. J. Dairy Sci. 2013, 96, 1549-1555. [CrossRef]

18. Voss, B.; Laue, H.-J.; Hoedemaker, M.; Wiedemann, S. Field-trial evaluation of an automatic temperature measurement device placed in the reticulo-rumen of pre-weaned male calves. Livest. Sci. 2016, 189, 78-81. [CrossRef]

19. Haladjian, J.; Haug, J.; Nüske, S.; Bruegge, B. A Wearable Sensor System for Lameness Detection in Dairy Cattle. Multimodal Technol. Interact. 2018, 2, 27. [CrossRef]

20. Jayaram, B.G. A Review on Cattle Health Monitoring in Wireless Sensor Networks (WSN). Int. J. Sci. Dev. Res. 2018, 3, 91-94.

21. Rahman, A.; Smith, D.V.; Little, B.; Ingham, A.B.; Greenwood, P.L.; Bishop-Hurley, G.J. Cattle behaviour classifi-cation from collar, halter, and ear tag sensors. Inf. Process. Agric. 2018, 5, 124-133.

22. Berckmans, D. Basic principles of PLF: Gold standard, labelling and field data. In The 6th European Conference on Precision Livestock Farming 2013; ECPLF: Austria, Vienna, 2013; pp. 21-29.

23. Bakare, A.; Ndou, S.P.; Madzimure, J.; Chimonyo, M. Predicting time spent on different behavioural activities from physicochemical properties of fibrous diets in finishing pigs. Appl. Anim. Behav. Sci. 2015, 167, 1-8. [CrossRef]

24. Firkins, J.L.; Yu, Z. RUMINANT NUTRITION SYMPOSIUM: How to use data on the rumen microbiome to improve our understanding of ruminant nutrition1,2. J. Anim. Sci. 2015, 93, 1450-1470. [CrossRef]

25. Difford, G.F.; Plichta, D.R.; Løvendahl, P.; Lassen, J.; Noel, S.J.; Højberg, O.; Wright, A.-D.G.; Zhu, Z.; Kristensen, L.; Nielsen, H.B.; et al. Host genetics and the rumen microbiome jointly associate with methane emissions in dairy cows. PLoS Genet. 2018, 14, e1007580. [CrossRef]

26. Das, R.; Sailo, L.; Verma, N.; Bharti, P.; Saikia, J.; Imtiwati, K.R. Impact of heat stress on health and performance of dairy animals: A review. Vet. World 2016, 9, 260-268. [CrossRef]

27. Sejian, V.; Indu, S.; Naqvi, S.M.K. Impact of short term exposure to different environmental temperature on the blood bio-chemical and endocrine responses of Malpura ewes under semi-arid tropical environment. Indian J. Anim. Sci. 2013, 83, 1155-1160.

28. Davison, C.; Michie, C.; Hamilton, A.; Tachtatzis, C.; Andonovic, I.; Gilroy, M. Detecting Heat Stress in Dairy Cattle Using Neck-Mounted Activity Collars. Agriculture 2020, 10, 210. [CrossRef]

29. Ramón-Moragues, A.; Carulla, P.; Mínguez, C.; Villagrá, A.; Estellés, F. Dairy Cows Activity under Heat Stress: A Case Study in Spain. Animals 2021, 11, 2305. [CrossRef]

30. Rutherford, N.H.; Gordon, A.W.; Lively, F.O.; Arnott, G. The Effect of Behaviour and Diet on the Rumen Temperature of Holstein Bulls. Animals 2019, 9, 1000. [CrossRef] 
31. Ivanov, Y.A.; Morozov, N.M.; Syrovatka, V.I. Technological requirements for new machinery in animal husbandry. Rosinformagrotech 2010, 11, 108.

32. Vtoryi, V.F.; Gordeyev, V.V.; Vtoryi, S.V.; Lantsova, E.O. Assessment of temperature and humidity state in cowsheds by means of graphical information modeling. VNIIMZh Bull. 2016, 4, 67-72.

33. AlZahal, O.; Kebreab, E.; France, J.; Froetschel, M.; McBride, B. Ruminal Temperature May Aid in the Detection of Subacute Ruminal Acidosis. J. Dairy Sci. 2008, 91, 202-207. [CrossRef] [PubMed]

34. Antanaitis, R.; Vida, J.; Rutkauskas, A.; Televicíus, M.; Stasiulevicíutēe, I. Reticuloruminal temperature and pH as indicators of the likelihood of reproductive success. J. Dairy Res. 2018, 85, 23-26. [CrossRef]

35. Dorokhov, A.; Ivanov, Y.; Kirsanov, V.; Pavkin, D.; Vladimirov, F. Diagnosing sub-acute rumen acidosis in cows in the post-calving period with digital technologies. Arq. Bras. de Med. Veterinária e Zootec. 2021, 73, 271-276. [CrossRef]

36. Soriani, N.; Panella, G.; Calamari, L. Rumination time during the summer season and its relationships with metabolic con-di-tions and milk production. J. Dairy Sci. 2013, 96, 5082-5094. [CrossRef] [PubMed]

37. Bessarabov, B.F.; Vashutin, A.A.; Voronin, E.S. Infectious Diseases at Animals; ColosS: Moscow, Russia, 2007 ; p. 671.

38. Isimbekov, Z.M.; Bulekbayeva, L.T.; Tarasovskaya, N.E. Practical Parasitology: Textbook for Students, Undergraduates, Doctoral Students of Biological and Agricultural Specialties; PGPI: Pavlodar, Kazakhstan, 2016; p. 323.

39. Wang, J.; He, Z.; Zheng, G.; Gao, S.; Zhao, K. Development and validation of an ensemble classifier for real-time recognition of cow behavior patterns from accelerometer data and location data. PLoS ONE 2018, 13, e0203546. [CrossRef] [PubMed] 